\title{
SPRICHWÖRTER IN DEN WERKEN VON GÁSPÁR HELTAI
}

\author{
Erzsébet FORGÁCS-DRAHOTA \\ Universität Szeged, Hochschulfakultät für Lehrerausbildung „Gyula Juhász“ \\ Lehrstuhl für deutsche Sprache und Literatur \\ H-6701 Szeged, Hattyas sor 10., Ungarn
}

\begin{abstract}
Proverbs from Gáspár Heltai - This essay examines the way Gáspár Heltai, one of the most important Hungarian writers and preachers in the Reformation period in the XVIth century, used proverbs in his works.

The author of this article compiled proverbs which were collected from 5 of Heltai's work. She shows that some of Heltai's proverbs are used even today as she compares Heltai's proverbs with the most sophisticated proverbs in the Hungarian language. Then she focuses on the contexts which were typical of Heltai's proverbs: first, she compares the literal meaning of the proverb with the symbolic meaning. Secondly, she examines the way Heltai collects many proverbs in one tale. Thirdly, she analyzes the way Heltai frames some of his stories with proverbs at the beginning and at the end of his work. Next, she describes the logical relationships between sentences in the text and demonstrates the function of the proverbs in these logical relationships. Finally, by using phraseological examples, the author reveals the linguistical influence of German (Heltai's native language) on these Hungarian proverbs.

Keywords: literalization, repetitive use of proverbs, logical relationship, proverbial minimum, interference, proverb, Gáspár Heltai, proverbs in literature
\end{abstract}

\section{EINFÜHRUNG}

Der Gegenstand meines Beitrags ist der Sprichwortgebrauch eines der bekanntesten Schriftsteller-Predigers des XVI. Jahrhunderts, von Gáspár HelTAI. Seine Werke sind an Phraseologismen dermaßen reich, daß sie mehrmals als Quellen diesbezüglicher Untersuchungen dienten. Nach Vilmos ToLNAIs treffender Bemerkung (1910: 29) sind Heltais Werke beinahe als Phraseologie-Sammlungen zu betrachten.

Diese Fülle an Phraseologismen kann auf mehrere Gründe zurückgeführt werden. Erstens ist es Ausdruck von seinem persönlichen Stil. Zweitens ist es dem Thema seiner Werke zu verdanken. Für die Fabeln ist z.B. schon von ihren gattungstypologischen Besonderheiten heraus eine lehrreiche Tendenz charakteristisch, d.h. sie enthalten viele knapp und treffend formulierte Lebensweisheiten, Verallgemeinerungen von gesellschaftlichen Erfahrungen. Dies gilt besonders für die Erläuterungen [értelmezés] am Ende der Fabeln, die HelTAI selbst verfaßt hat, um die Lehre der Fabeln noch eindeutiger darzustellen. Sein Dialógus ist zwar mit Elementen der schöngeistigen Literatur durchwebt, im Grunde genommen ist es aber doch ein geistlich-moralisierendes Werk, und eben mit dieser moralisierenden Tendenz ist 
zu erklären, daß der nüchterne Antal viele Sprichwörter verwendet, wenn er den Trunkenbold Demeter zu Mäßigkeit und Enthaltsamkeit zu erziehen versucht. Es ist wiederum einsichtig, warum wir in den Geschichten der sieben weisen Lehrer in Ponciámus császár históriája so viele Sprichwörter finden, denn es brauchte schon einer besonderen Redekunst, Diocleciánus von den hinterlistigen Intrigen seiner Stiefmutter zu retten. In seiner Abhandlung Háló, in der er die spanische Inquisition entlarvte, sind wiederum viele Phraseologismen zu finden. Sein Werk Krónika hat einen geschichtlichen Charaker, deshalb ist es im Verhältnis zu den anderen arm an Phraseologismen.

Drittens soll darauf hingewiesen werden, daß die Zeit der Reformation als das goldene Zeitalter des Sprichwortes als Folklorgattung galt. Die Reformation war nämlich das Zeitalter, in dem die Sprichwörter ihre Aufgabe am besten erfüllen konnten: Die waren dazu berufen, die Menschen in ihrem Handeln, Denken und in ihrer Überzeugung zu lenken. Den schriftlichen Gesetzen und den ethischen Normen ähnlich versuchten sie zu helfen, zwischen Sünde, Lasten und Tugend zu unterscheiden, sie versuchten mit Warnungen und Verboten Ratschläge für den Alltag zu geben. ${ }^{1}$ Sowohl Priester in höheren Positionen als auch Geistlichen in den kleinen Dörfern haben in ihren Predigten Sprichwörter verwendet, da diese als Teil der Bauernkultur galten, und so konnte der Prediger fest damit rechnen, daß seine Worte verstanden wurden. In einem Zeitalter, in dem an der Evidenz der altertümlichen Weisheiten nicht gezweifelt wurde, wurden sie selbstverständlich öfter verwendet. ${ }^{2}$ Die Sprichwörter hatten nicht nur in der Kindererziehung, sondern sogar im Rechtswesen, in den unterschiedlichen Rechtsstreiten eine wichtige Rolle. ${ }^{3}$

\footnotetext{
${ }^{1}$ Das Gesagte gilt natürlich nicht für jedes Sprichwort in gleichem Maße, da nicht jedes Sprichwort eine Weisheit mit lehrhafter und erzieherischer Tendenz ausdrückt (vgl. die Beispiele von SZEMERKÉNYI 1994: 39). TOlnaI (1935: 402 f.) unterscheidet drei Arten der Sprichwörter abhängig davon, ob sie 1) eine Feststellung [megállapítás] aufgrund unparteilicher Beobachtung ausdrücken ohne Urteil und Erläuterung oder 2) die Wertung sich schon im Urteil [ítélet] äußert, bzw. 3) ob sie einen auf Beobachtung beruhenden Ratschlag [tanács] ausdrücken.

Die Rolle der Sprichwörter besteht nach SZEMERKÉNYI (1988: 219 f.) darin, eine zukünftige Handlung mit dem Verweis auf eine vergangene Erfahrung zu beeinflussen. Diese Beeinflussung kann mit einer einfachen Feststellung [megállapítás] geschehen, oder mit Bewertung [értékelés], oder mit Vorschrift [előírás].

Über den Einfluß der Sprichwörter auf das menschliche Handeln siehe noch DETJE (1995), der nachweist, daß viele Sprichwörter den zehn Stationen der Handlungsorientation - wenn auch nicht in gleicher Weise bzw. in gleichem Maße - zugeordnet werden können (diese sind: Absichtsbehandlung; Zielausarbeitung; Informationssammlung; Prognose, Erwartungshorizont; Modellbildung; Planen; Übergang vom Planen zum Tun; Handeln; Effektkontrolle und Selbstreflexion). Auf diese zehn Stationen verteilt werden in den Sprichwörtern etwa 111 verschiedene Themen der Handlungsorganisation angesprochen (vgl. DETJE a.a.O. 115).

2 Nach SZEMERKÉNYI (1994: 102) sei für die Verwendung von Sprichwörtern entscheidend, ob wir an ihrem Wahrheitsgehalt glauben, ob wir sie - verglichen mit unseren Erfahrungen - für wahr und treffend halten.

${ }^{3}$ Vgl. TOLNAI 1935: 405 und SZEMERKÉNYI 1994: 77 ff. Im Mittelalter sind zahlreiche Werke z.B. für Jugendliche, Eheleute usw. entstanden, die durch Parömien zur moralischen Erziehung dienten und Ratschläge für tägliche Probleme gaben (vgl. dazu z.B. SZEMERKÉNYI 1994: 119 ff.).
} 


\section{THEMA UND ZIELE DES BEITRAGS}

In einer größeren Arbeit - unter anderen Aspekten - habe ich mich schon mit den Proverbien (Redewendungen und Sprichwörtern) HELTAIs beschäftigt, und zu dieser Untersuchung habe ich eine Phraseologie-Sammlung zusammengestellt, die aus 75 Sprichwörtern (in 96 Verwendungen) und aus 211 Redewendungen (in 333 Verwendungen) bestand. Als Quelle für diese Sammlung dienten die bereits erwähnten fünf Werke HeltaIs. ${ }^{4}$ Dieses Korpus habe ich wieder in die Hand genommen, diesmal mit der Absicht, in erster Linie die Sprichwörter (Parömien) ${ }^{5}$ zu untersuchen.

Die Untersuchung der Sprichwörter ist auf mehreren Ebenen möglich, von denen hier natürlich nicht auf alle eingegangen werden kann. Mein Beitrag verfolgt die folgenden Ziele: Nachdem einige Fragen der Identifikation angesprochen wurden, wird der Versuch unternommen, HELTAIs Sprichwörter mit dem heutigen Ungarisch zu kontrastieren. Dann wird auf diejenigen Einbettungsmöglichkeiten der Sprichwörter im Kotext fokussiert, die für HeLTAI typisch sind: Erstens wird die Literalisierung, zweitens die Sprichwörterhäufung und drittens die rahmenhafte Anordnung der Sprichwörter unter die Lupe genommen. Es wird durch die Darstellung der inhaltlich-logischen Beziehungen zwischen den Sätzen im Textabschnitt untersucht, was für eine Funktion HelTAI seinen Sprichwörtern im Text beimißt. Die Platzierung der Sprichwörter im Text wird auch schematisch dargestellt. Zum Schluß werde

Es sei nur in Klammern darauf hingewiesen, daß der Wahrheitsgehalt der Sprichwörter im modernen Sprachgebrauch oft in Frage gestellt wird. Die Sprichwörter haben an ihrer Gültigkeit eingebüßt und ihre erzieherische Kraft ist auch nicht mehr unbestritten. Sprichwörter werden heute vielfach als abgenutzte Gemeinplätze abgetan, denn - wie MACKENSEN (1985: 87) sagt - „die meisten Sprichwörter verkünden Binsenwahrheiten, die noch dazu anfechtbar sind. Machte sich einer daran, eine Ethik der Sprichwörter zu schreiben, aus seinem Buche sähe das etwas dümmliche Spießergesicht des ewigen Besserwissers auf den Leser." Mit dieser Haltung den Sprichwörtern gegenüber kann wohl erklärt werden, daß im heutigen Sprachgebrauch die Sprichwort-Parodie, d.h. die ironisierende, meist spielerische Verdrehung der alten Sprichwörter ein beliebtes Stilmittel geworden ist. Hier nur einige Beispiele: Aki árt mond, mondjon bért is; Amit ma megvehetsz, ne halaszd holnapra; Kicsi a bors, de drága (vgl. SZATHMÁRI 1996: 461. Über die Sprichwort-Persiflagen, die aus der Kontamination von mehreren Sprichwörtern entstanden sind, siehe z.B. DÖMÖTÖR 1989: 128 und HERNÁDI 1976: 15). (Zur spielerischen Verwendung der Sprichwörter im heutigen Sprachgebrauch siehe z.B. FoRGÁCs 1997a, 1997b und 1997c.)

${ }^{4}$ Diese fünf Werke sind die folgenden: 1. A bölcs Esopusnak és másoknak oktató beszédei...; 2. A részegségnek és tobzódásnak veszedelmes voltáról való dialógus; 3 . Háló; 4. Krónika az magyaroknak dolgairól und 5. Ponciánus császár históriája. Bei Zitaten verwende ich die folgenden Abkürzungen: Fabeln; Dialógus; Krónika und Ponciánus, und ich gebe nur die Seitenzahl an. (Die genauen Literaturangaben siehe im Literaturverzeichnis bei der Primärliteratur.)

${ }^{5}$ Zur Definition des Sprichwortes vgl. DetJE 1995: 97; MACKENSEN 1985: 86 f. und MATTA 1988: 71; zur Abgrenzung des Sprichwortes zu anderen festgeprägten Konstruktionen (Sagwort, Sentenz, Maxime, Aphorismus und sprichwörtliche Redensarten) vgl. FLEISCHER 1982: 80 ff. und FLEISCHER/HARTUNG/ SCHILDT/SUCHSLAND 1983: 314. Zu terminologischen Fragen in der ungarischen Fachliteratur siehe z.B. die Übersichten bei O. NAGY 1977 und SZEMERKÉNYI 1994: 8 ff. oder vgl. noch BENCÉDY/FÁBIÁN/ RÁCZ/VELCSOVNÉ 1985: 494 ff. und JUHÁSZ 1980: 91. Sprichwörter betrachte ich als eine Gruppe der Proverbien, d.h. der sprachlichen Einheiten, die ihre charakteristischen Merkmale in der Mehrgliedrigkeit/Polylexikalität und in der relativen Festigkeit haben, wobei das Kriterium der Idiomatizität nicht unbedingt erfüllt werden muß. 
ich versuchen, die deutsche Muttersprache HELTAIs anhand seiner Phraseologismen nachzuweisen. Auf eine mögliche thematische Klassifizierung der Sprichwörter muß hier - aus Platzgründen - verzichtet werden.

\section{HELTAIS SPRICHWÖRTER - ZU DER FRAGE DER IDENTIFIKATION}

2.1. Wie vorhin erwähnt, habe ich in den untersuchten fünf Werken 75 Sprichwörter gefunden. Da es sich hier um Texte aus dem XVI. Jh. handelt, können zahlreiche Sprichwörter, die HELTAI noch verwendet hat, seitdem veraltet und aus unserer Sprache ausgestorben sein. ${ }^{6}$ Diesen Verdacht haben wir, wenn ein sprichwortartiges Gebilde mehrmals in fast derselben komprimierten Form und mit nahezu demselben semantischen Gehalt vorkommt, z.B.:

„E fabulával mutatá meg a bölcs Esopus a világi dúsoknak és kegyetleneknek hamisságát és kegyetlenségét, hogy azok nem gondolván sem az Úristennel, sem annak igazságával, a szegény ártatlanokat minden ok nélkül megnyomorítják. Veszett nevét költik az ebnek, csakhogy megölhessék. Vagy megette a hájat az eb vagy nem, de mindenképpen pálcát keresnek neki. Pauper ubique iacet. Vagyis: A szegény mindenhol az portban hever." = 'auch wenn jemand nicht schuldig ist, wird ein Grund gefunden, warum er bestraft werden kann'. (Fabeln 10). ${ }^{7}$

„E fabula inti a szegényeket és az alsó renden valókat, hogy az ő állapotjukban megmaradjanak s feljebb való rendre ne igyekezzenek hágni. És hogy megelégedjenek avval, amit az Úristen az ô jóvoltából nekik ád, noha nem igen sok az. Ne társalkodjanak egybe a nagy dúsokkal és dölyfösökkel, mert nem egybevalók ők. Hamar megváltoznak a nagy urak és legott kész a pálca. Ahogy közbeszéddel mondják: Vagy megette az eb a hájat, avagy nem, mindenképpen bünös. " $=$ vgl. oben $\left(\right.$ Fabeln 146) ${ }^{8}$

${ }^{6}$ Zur Identifikation der Belege habe ich in den folgenden Sammlungen nachgeschlagen: bei BARANYAI DECSI, János (1598), BARÓTI SZABÓ, Dávid (1803), ERDÉlYI, János (1851), MARGALITS, Ede (1897) und KERTÉSZ, Manó (1922), außerdem habe ich gelegentlich auch das ungarische etymologische Wörterbuch (Magyar nyelvtörténeti szótár 1890, abgekürzt NySz.) zur Hilfe genommen. Ich habe auch die Sammlung von O. NAGY (1976) verwendet, denn diese ist zur Zeit die umfangreichste (enthält nahezu 20000 Sprichwörter und Redensarten) und O. NAGY hat all die anderen früheren Sammlungen verwendet, sogar viele Werke HELTAIs dienten ihm zur Grundlage (z.B. Száz fabula, Dialógus, Háló und Krónika; vgl. O. NAGY 1976: 27). Da jedoch O. NAGY die älteren Belege selektieren mußte, und da er keine literarischen Quellen angibt, kann diese Sammlung zur Identifikation der Belege schließlich nicht verwendet werden.

${ }^{7}$ Hier bereits ein Beispiel für die Sprichwörterhäufung. Dazu siehe ausführlicher unter Punkt 5.2.

8 Vgl. NySz. 1890: 1250, wo dieser Eintrag unter den Redensarten vorkommt. 
2.2. Sprichwörter werden als Mikrotexte - wie im vorangehenden Beispiel - oft mit Hilfe von einem einleitenden Satz in den Text integriert. Das Vorhandensein solcher einleitender Sätze spricht dafür, daß wir es mit einem Sprichwort zu tun haben. Diese Annahme erscheint auch deshalb als berechtigt, weil auch von den Sprichwörtern, die in Sammlungen vorzufinden waren, ziemlich viele (etwa 25) ähnlich eingeleitet werden, z.B.: „És így teljesedik bé a közmondás: Vonsszon a fakó! De ismét a fakót is vonsszák." = "das Schlechte wird mit Schlechtem heimgezahlt' (Fabeln 84).

Ich habe 9 solche Belege als Sprichwörter bewertet, die in den Sammlungen zwar nicht vorzufinden waren, die aber HELTAI wie folgt einleitet: Azért szokták mondani közbeszéddel (Fabeln 104); Innen vagyon ama közmondás is, hogy... (Dialógus 27); Azért mondották a régiek, hogy... (Fabeln 32); Jól mondották a régi példabeszédben, hogy... (Ponciánus 302); Így szóltak a régi magyarok is... (Fabeln 109); Erre mondották a régi jámborok... (Fabeln 115). Diese einleitenden Sätze berufen auf die allgemeine Bekanntheit der Sprichwörter und wollen jeden Zweifel an ihrer Gültigkeit aufheben. Der Empfänger soll wissen, daß die Aussage eigentlich nicht vom Sender verfaßt wurde, sondern eine tradierte Aussage ist und somit nicht die Wertvorstellungen des Senders allein darstellt. Derartige „Erfahrungssätze“ (MATTA 1988: 70) vermitteln allgemeingültige Wertmaßstäbe, denen jeder folgen soll, oder welche jeder beherzigen soll, z.B.:

„E fabula azt jelenti, hogy senki ne ítélje magát igen bölcsnek és hogy senki tanácsát meg ne útálja és meg ne vesse. Mert noha más ember hozzánk képest gyarló és szegény is, talán azért ugyan ő is ember és Istennek eszköze... Azért mondották a régiek, hogy nem csak az ártány, hanem még az emse disznó is tud szép makkot

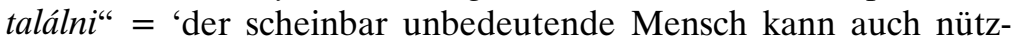
liche Ratschläge geben' (Fabeln 32). ${ }^{9}$

\section{HELTAIS SPRICHWÖRTER HEUTE}

Obwohl von HELTAIs Sprichwörtern viele bereits ausgestorben sind, gibt es dennoch viele, die auch heute bekannt sind. Wenn ich mein Korpus mit dem Sprichwortbestand des heutigen Ungarisch vergleiche, komme ich zum folgenden Ergebnis: Von den 75 Sprichwörtern sind etwa 41 auch heute noch bekannt, d.h. die gehören zum Parömium-Bestand des heutigen Ungarisch. Diese Feststellung bedarf allerdings einer Einschränkung. Wenn wir nämlich den stilistischen Wert dieser Sprichwörter betrachten, sehen wir, daß sie nahezu alle bereits archaisch wirken und demzufolge einer gewählten, gehobenen Stilschicht angehören. Die Mehrheit dieser Sprichwörter wird also zwar passiv verstanden, aber aktiv nicht mehr oder nur selten verwendet, z.B.:

${ }^{9}$ Dieser Beleg ist auch bei HADROVICS (1995: 240) vorzufinden. 
Ha valaki varjat akar löni, ne pengesse az îjjnak idegét elótte. = 'wenn jemand seinen heimlichen Plan verwirklichen möchte, sollte darüber nicht reden'. (Fabeln 54.).

Mikor hámlik a hárs, akkor kell azt hántani. = 'man soll alles dann verwirklichen, wenn die Umstände günstig sind'. (Fabeln 155).

Des Weiteren habe ich HelTAIs Sprichwörter, bzw. diejenigen, die im heutigen Ungarisch bekannt sind, mit dem parömiologischen Minimum des Ungarischen verglichen. Dazu habe ich die Forschungsergebnisse von TóTH-LITOVKINA (1996) verwendet. Anhand ihrer Untersuchungen können 158 Sprichwörter zum Bestand des parömiologischen Minimums des Ungarischen gezählt werden. Das sind alle solche Parömien, die für minimum 90,2\% der Sprecher mit ungarischer Muttersprache bekannt sind. Nach dem Vergleich bin ich zu dem folgenden Ergebnis gelangt:

Von den 75 Sprichwörtern HelTAIs sind heute etwa fünf Sprichwörter Teil des parömiologischen Minimums. Diese sind in der Reihenfolge ihrer Bekanntheit die Folgenden: ${ }^{10}$

1. Hogyha valaki a más ember lovának vermet ás, az önnön maga lovának nyaka szegetik meg benne. = 'wenn jemand einem anderen Schaden zufügen möchte, schadet dadurch oft sich selbst'. (Fabeln 12). (Vgl. O. NAGY 1976: 721./369.: Aki másnak vermet ás, maga esik bele.) (Bekanntheitsgrad: 100\%)

2. Lassan érnek messze. = 'mit Überlegenheit, Ausdauer und genauer Arbeit kann man besser vorwärtskommen als mit unüberlegter Eile'. (Fabeln 38). (Vgl. O. NAGY 1976: 424./231.: Lassan érünk messzire.) (Bekanntheitsgrad: 99,8\%)

3. Többet ér az okosság és a bölcsesség az nagy erônél. = 'mit Überlegung kommt man weiter als mit purer Gewalt'. (Fabeln 146.) (Vgl. O. Nagy 1976: 183./748.: Többet ésszel, mint erôvel; Az ész nagyobb az erónél.) (Bekanntheitsgrad: 95,2-99,5\%)

4. Adós fizet. $=$ 'unsere Schulden müssen wir bezahlen'. (Dialógus 53). (Vgl. O. NAGY 1976: 35./97.: Adós fizess (, ne nevess, ez a feketeleves)!) (Bekanntheitsgrad: 90,2-95,0\%)

5. Nem jó az urakkal egy tálból cseresznyét enni. Merthogy legott lövöldözni kezdenek a magokkal. $=$ 'die armen Menschen sollten die Gesellschaft der Reichen vermeiden, da sie früher oder später auf die Freundschaft draufzahlen'. (Fabeln 77). (Vgl. O. NAGY 1976: 699./97.: Nem jó nagy urakkal egy tálból cseresznyét enni, mert a magvával kiverik az ember szemét / mert meglö / meglövöldöz a magvával.) (Bekanntheitsgrad: 90,2-95,0\%)

\footnotetext{
${ }^{10}$ Ich werde nach dem Beleg jeweils den Bekanntheitsgrad nach den Untersuchungen von ТóтHLITOVKINA (1996) angeben.
} 


\section{HELTAIS SPRICHWÖRTER IM KOTEXT}

Nachdem die Bekanntheit von HeLtAIs Sprichwörtern angesprochen wurde, sollte nun ihre Einbettung im Kotext untersucht werden. Der Sprachtstil eines Schriftstellers kann nämlich nicht nur dadurch charakterisiert werden, wie viele Sprichwörter er verwendet, sondern auch dadurch, wie er diese im Kotext plaziert. Sowohl die Häufigkeit des Vorkommens als auch die Plazierung im Kotext sind damit im engen Zusammenhang, was für eine Funktion die Sprichwörter zu erfüllen haben. Dies hängt wiederum nicht nur vom jeweiligen Schriftsteller ab, sondern wie am Anfang bereits darauf hingewiesen - auch vom Sprachusus der Zeit und überhaupt davon, was für eine Rolle Sprichwörtern in einer gegebenen Epoche beigemessen wird.

\subsection{LITERALISIERUNG}

Bevor größere Textabschnitte unter die Lupe genommen werden, soll auf eine besondere Verwendungsweise der Sprichwörter eingegangen werden, und zwar auf die Literalisierung. Wie allgemein bekannt, gehören Sprichwörter nach der Meinung vieler Linguisten deshalb nicht zu den Phraseologismen im engeren Sinne, da nicht alle von ihnen eine metaphorische Bedeutung haben. Innerhalb der Sprichwörter können bekanntlich - im Zusammenhang mit der Idiomatizität - zwei Gruppen unterschieden werden: 1) die eine Gruppe bilden Sprichwörter, deren Bedeutung sich aus den Bedeutungen der Komponenten erschließen läßt, z.B.: Olyan a tanyítván, mint a Mester (Háló 191); Jótétel hellyébe jót ne várj (Fabeln 20); Az éhség kedig az igen jó szakács (Dialógus 59); 2) in die andere Gruppe gehören solche Sprichwörter, deren Bedeutung mit der Summe der Bedeutungen ihrer Komponenten nicht mehr identisch ist, die also eine semantisch transformierte Bedetung haben, z.B.: Az sárban hevert disznó azt akarná, hogy a többi is mind sáros volna (Ponciánus 302); Nem szükség, hogy a tetüt beoltsák a ködmenbe, mert anélkül is csak könnyen megterem benne (Dialógus 16); ${ }^{11}$ Az tehén és az borjúhús nem fó egyforma puhára egyazon fazokban (Fabeln 120). ${ }^{12}$

Wie die letzten drei Beispiele zeigen, können manche Sprichwörter sowohl idiomatisch als auch nicht-idiomatisch verwendet werden. In diesem Sinne sind sie polysem. Durch das Bewußtmachen dieser Polysemie können unterschiedliche kommu-

\footnotetext{
${ }^{11}$ Die aktuelle kontextuelle Bedeutung des Sprichwortes bei HELTAI ist: 'man braucht dem Menschen das Schlechte nicht beizubringen, da es schon von Geburt an in ihm gegeben ist'. Dagegen bei O. NAGY (1976: 672./425. - allerdings mit Fragezeichen): 'man braucht das Übel nicht zu suchen, das passiert von sich selbst'.

12 BURGER (1973: 10) spricht über idiomatisch-phraseologische (kurz: idiomatische) und über nichtidiomatisch phraseologische (kurz: nur-phraseologische) Verbindungen. JUHÁsz (1980: 90) weist darauf hin, daß Sprichwörter - auch wenn sie nicht voll idiomatisch sind - genauso auf Integration beruhende Bedeutungseinheiten repräsentieren wie die anderen phraseologischen Einheiten.
} 
nikative Intentionen erzielt werden ${ }^{13}$ Für den Stil HeLTAIs ist charakteristisch, daß er die metaphorische Ebene der Sprichwörter oft verläßt und die wörtliche Bedeutung des Sprichwortes in einem konkreten Bild evoziert. Bei diesem Spiel verlaufen zwei entgegengesetzte semantische Prozesse: Demotivation und Remotivation. Im Prozeß der Demotivation entstehen Idiome, indem die wörtliche Bedeutung der Wendung aufgehoben wird, und die Remotivation ist der Proze $\beta$ in umgekehrter Richtung, in dem man versucht, die Bedeutung der Wendung aus den einzelnen Komponenten zu erschließen. ${ }^{14}$ Die Remotivation erscheint selbstverständlich bei den Sprichwörtern besonders einfach, die auch als freie Wortgruppen auftreten können, in denen also jedes Wort für sich und nicht als Teil der phraseologischen Einheit stehen kann, d.h. wo der Wortcharakter der Konstituenten leicht wieder hergestellt werden kann. ${ }^{15}$ Die sinnvolle „wörtliche“, „sich additiv ergebende Bedeutung" wird literale (vgl. lat. litera ,Buchstabe') Bedeutung genannt (vgl. KOLLER 1977: 12f.). Den Prozeß, in dem die wörtliche Bedeutung der Wendung aktualisiert wird, nennt man Literalisierung. Das Literalisierungsspiel beruht also auf der potentiellen Doppelbödigkeit phraseologischer Wendungen. ${ }^{16}$ Sehen wir nun ein Beispiel von HELTAI:

„Ezokáért szükséges, ha azt akarod, hogy valami jót és hasznos dolgot cselekedjen a te házad népe, hogy jó sompálca és bot legyen kezedben és avval birjad le gonosz keménységüket. Azért mondották a régiek: Malo nodo malus querendus est cuneus. Vagyis: $\mathrm{Ke}$ mény göcshöz kemény ék való. A gonosz göcses fát, ha meg akarod hasítani, bizony sulyok és vasék kell hozzá." = "für die schwer erreichbaren Ziele soll man wirkungsvolle Mittel einsetzen'. (Fabeln 116).

\subsection{SPRICHWÖRTERHÄUFUNG}

Phraseologische Einheiten können auf unterschiedliche Weise in den Text eingebaut werden: sie können als selbstständige Sätze erscheinen, oder sie können als Teil eines zusammengesetzten Satzes erscheinen, und zwar auf der Ebene des Hauptsatzes oder auf der Ebene des Nebensatzes. Ihre Bestandteile können auch zerstreut im Text vorkommen. Diese potentielle Vielfalt der Einbettung der Phraseologismen ist für Sprichwörter dennoch nicht so sehr charakteristisch. Sprichwör-

\footnotetext{
${ }^{13}$ Die Möglichkeit der zwei Interpretationen soll einen „Aha-Effekt" hervorrufen, Aufmerksamkeit erregen, deshalb sind Literalisierungsspiele in der Werbesprache sehr beliebte Stilmittel. Über Literalisierungsspiele in der Sprache der deutschen und ungarischen Werbung und in deutschen Witzen siehe z.B. FORGÁCS 1996 und 1997b.

14 Zum Verhältnis der Demotivation und Remotivation vgl. HESSKY 1992: 90.

${ }^{15}$ In solchen Fällen spricht BURGER (1973: 29) über „umgekehrte Metaphorisierung“.

${ }^{16}$ HESSKY (1992: 85) spricht bei solchen phraseologischen Einheiten über „(synchronische) Motiviertheit“" und versteht darunter „,das Nebeneinander einer 'wörtlichen' und einer 'phraseologischen Lesart' derselben Wortverbindung, eine Ambiguität“.
} 
ter geben nämlich einen abgeschlossenen Gedanken wider und sie stellen schon an sich die Beziehung des Sprechers zur Wirklichkeit dar. Sprichwörter haben die Form und den Wert eines Satzes: Sie sind abgeschlossene Mikrotexte (vgl. HÄUSERMANN 1977: 41). Diese Mikrotexte werden wie Zitate behandelt, deshalb werden sie in der überwiegenden Mehrzahl der Fälle als selbstständige Sätze in den Text eingebaut. Dies ist auch für HELTAI weitgehend charakteristisch.

Im Falle einer bewußten Textgestaltung hängt die Platzierung des Sprichwortes im Text davon ab, was für eine Rolle es zu erfüllen hat. In dem Textzusammenhang konkretisiert sich die aktuelle Bedeutung. Deshalb werden wir des Weiteren zwei Textabschnitte als größere Einheiten der Gedankenvermittlung untersuchen, in denen mehrere Sprichwörter vorzufinden sind. ${ }^{17}$

(1) E fabula elóször azt jelenti, mely igen ritkán találtatik egy hívbarátja avagy rokonsága az emberek között.

(2) Azért szokták mondani közbeszéddel: Mikor barátjára az embernek szüksége vagyon, akkor ötven is reáfér egy fontnyi mértékre.

(3) Ennekutána arra tanít a fabula, hogy kiki mind ô maga lásson dolgához és másra ne bízza azt.

(4) Mert legott megcsalatkozik.

(5) Másnak nem fáj a te fejed.

(6) Bizony nem gondol vele, mert nem az övé.

(7) Ezokáért, ha üsződ a sárban dől, te magad fogd a farkát és te magad emeljed erósen.

(8) Mert ha temagad hozzá nem nyúlsz, bizony kétség nélkül odahal a sárban.

(9) Ha ezokáért a gazda azt akarja, hogy jó elómenetele legyen az ô dolgának, szükséges, hogy ô maga legyen a szolga.

(10) Ezért mondták a régiek: Micsodától hízik igen a ló?

(11) Feleltenek: Az családos embernek szemétól, azaz, ha ö maga szünetlen látja, mint bánnak a szolgák a lovakkal.

(12) Mert ha a gazda ô maga nem lát hozzá, csakhamar olyan leszen a ló, hogy minden oldalcsontját megszámlálhatod.

(13) Ismét mitól zsirosodik igen a szántóföld?

(14) Felelének a régiek: Az ganéjtól, mellyet a gazda saruival viszen reája.

(15) Ezzel azt jelentették, hogy ha a gazda gyakorta megyen a szántóföldre és ugyancsak megnézi, miképpen szántanak, miképpen vetnek és boronálnak az béresek, tehát nyilván jó gabonája lészen.

[(16) Így vagyon!] (Fabeln 103).

\footnotetext{
${ }_{17}$ Den Abschnitt teile ich in Sätze und gebe sie in einer nummerierten Folge an, um die zeitliche Aufeinanderfolge anschaulicher darstellen zu können. (Satz wird im Sinne von DEME 1971: 39 verwendet.)
} 
Der erste Satz des Textes ist ein Thesensatz, in dem HeLTAI die erste Lehre des Märchens formuliert. Im zweiten Satz wird derselbe Gedanke nun in Form von einem Sprichwort bestätigt und bekräftigt. Der dritte Satz trägt wiederum eine Grundinformation, die im Text eine genauso wichtige Nachricht enthält wie der erste Satz. All die anderen nachfolgenden Nebeninformationen enthaltenden Sätze sind - auch wenn indirekt - mit diesem Knoten verbunden. Im vierten Satz wird der Grund formuliert, im fünften finden wir wieder ein Sprichwort, mit dem der Wahrheitsgehalt des vorher Gesagten unterstützt wird. Der sechste Satz erklärt den vorherigen, der siebte folgt aus dem sechsten, und der achte erläutert wieder. Damit die Kette erhaltenbleibt: Der neunte Satz ist wiederum eine Schlußfolgerung, und gleichzeitig auch eine Rückkoppelung zum zweiten Thesensatz. Das bisher Gesagte wird im zehnten und elften Satz wieder mit einem Sprichwort veranschaulicht. Die Bedeutung dieses Sprichwortes ist: 'man kommt dann vorwärts, wenn man die Angelegenheiten selbst in die Hand nimmt'. Um die stilistische Wirkung zu erhöhen, knüpft sich Heltai nicht an die übertragene Bedeutung, sondern an das konkrete Bild, das im Sprichwort enthalten ist. Er literalisiert das Sprichwort, d.h. neben der phraseologischen Bedeutung evoziert er auch die konkrete, die denotative Bedeutung. Im dreizehnten und vierzehnten Satz finden wir wiederum ein Sprichwort, es ist interessant, daß die formale Lösung mit der des vorangehenden Sprichwortes identisch ist: das Sprichwort wird in zwei Sprechakten geteilt: in eine Frage und in eine Antwort. Dieses Sprichwort wird ebenfalls erläutert. Zwischen den Sätzen des Textes können in ihrer linearen Reihenfolge die folgenden inhaltlich-logischen Beziehungen ${ }^{18}$ unterschieden werden:

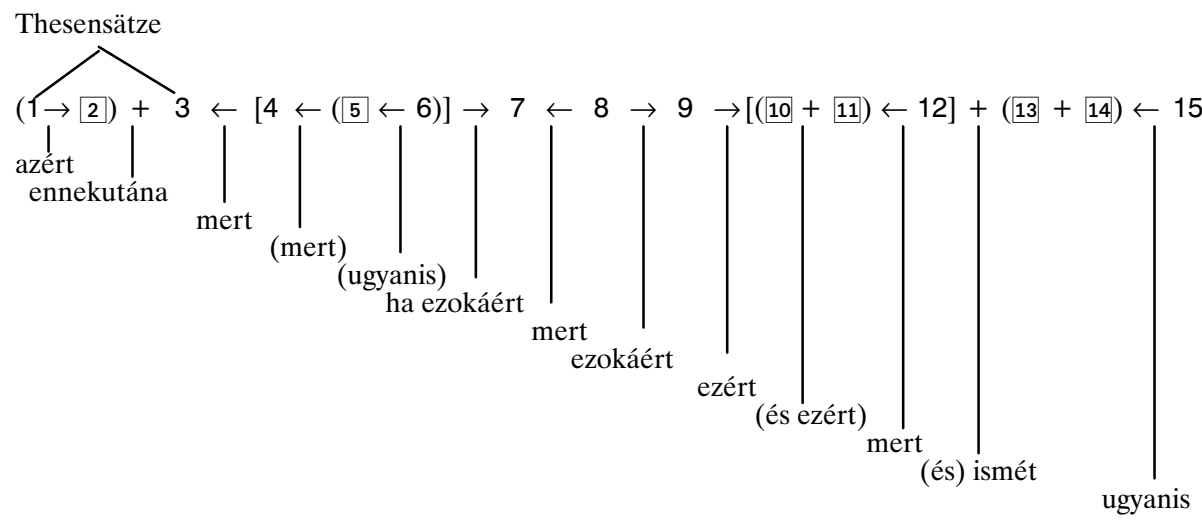

\footnotetext{
18 Über die inhaltlich-logischen Beziehungen siehe z.B. DEME 1965: 294; BÉKÉSI 1982: 47 f.

Die Nummer der Sätze, die Sprichwörter enthalten, habe ich markiert, um ihren Platz im Absatz besser veranschaulichen zu können. Die Konjunktionen in den Klammern kommen im Text nicht vor, wären allerdings sinnvoll und verdeutlichen die Beziehungen zwischen den Sätzen. Das sind nach außen verknüpfende (,kifelé kapcsoló“ - DEME ebenda) Konjunktionen, d.h. solche, die über den Satz hinaus den inhaltlich-logischen Beziehungen zwischen den Sätzen entsprechen. Diese sind meistens unterschiedliche parataktische Relationen.
} 
Wir sehen, daß im Text die konsekutiven und die kausalen Beziehungen dominieren, was daraus resultiert, daß HeLTAI das Sprichwort entweder als abschließende Zusammenfassung verwendet oder geht in seiner Darlegung eben vom Sprichwort aus. Aus dieser Sicht ist der Status des in den dreizehnten und vierzehnten Satz verteilten Sprichwortes sehr interessant: Es weist auf den neunten Satz zurück, da aber dieser mit dem dritten Satz als Thesensatz in Verbindung steht, zwar indirekt, aber knüpft sich auch auf den zurück. Einerseits steht also das Sprichwort als die Summierung des vorher Gesagten, andererseits wird es im fünfzehnten Satz wiederum selbst erläutert, in dieser Relation ist es also als Ausgangspunkt zu betrachten. Die inhaltlichen, gedanklichen Verbindungen der Sätze können mit einem Netzdiagramm wie folgt dargestellt werden: ${ }^{19}$

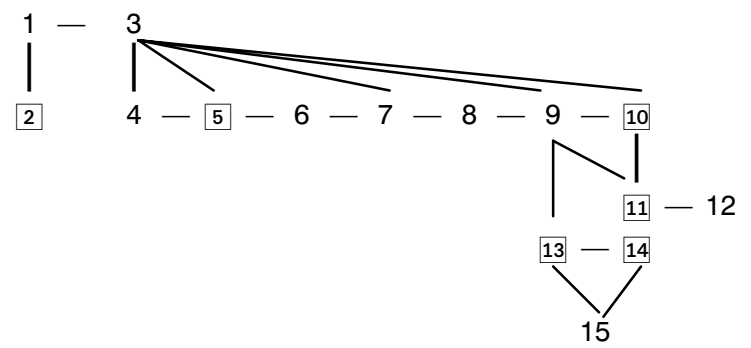

Im zitierten Textabschnitt sind vier synonyme Sprichwörter zu finden. Die Häufung von Sprichwörtern ist HELTAIs charakteristisches Stilmittel. Sie ist besonders in seinen Auslegungen zu den Fabeln zu beobachten, welche - wie bereits betont keine Übersetzungen sind, sondern von ihm verfaßt wurden. Den besonderen Wert der Auslegungen faßt HELTAI in seinem Vorwort wie folgt zusammen: „... nemcsak a puszta fabulákat szerzettem egybe, hanem minden fabulának az értelmét is melléje tettem s megtúzdeltem és meg is ékesítettem azokat szent írásokkal és egyéb szép, bölcs mondásokkal és közbeszédekkel“ (Fabeln 7). Manche Auslegungen sind länger als die Fabel selbst und sie sind voll mit Sprichwörtern, z.B. die Auslegung zur Fabel A keselyúról meg egyéb apró madarakról (vgl. Fabeln 146 - die Fabel besteht aus gut 5 Zeilen, die Auslegung aus fast 14 Zeilen): „Hamar megváltoznak a nagy urak és legott kész a pálca. Ahogy közbeszéddel mondják: Vagy megette az eb a hájat, avagy nem, mindenképpen bünös. Ezt is mondották a régiek: Nem jó a nagy urakkal egy tálból cseresznyét enni, mert legott homlokodra lövöldözik a magokat.“20

\footnotetext{
19 Über die Verwendung des Netzdiagramms in der Textologie siehe RozGONYI 1978. Das Netzdiagramm ermöglicht, die Beziehungen nicht nur unter den aufeinanderfolgenden Sätzen zu veranschaulichen, sondern auch die Beziehungen zwischen den Sätzen an unterschiedlichen Stellen des Absatzes.

${ }^{20}$ Wenn man die Fabeln mit ihren Auslegungen der Länge nach vergleicht, sieht man, daß in 82 Fällen die Fabeln, in 18 Fällen jedoch die Auslegungen länger sind. Es kommen allerdings auch solche Fabeln vor, die sehr kurz sind (z.B. die erste Fabel hat nicht einmal vier Zeilen), und es gibt auch sehr lange Auslegungen (z.B. zur Fabel „Az oroszlánról meg a majomról““ - Fabeln 53 f. - 49 Zeilen).
} 
Eine besondere Art der Sprichwörterhäufung ist, wenn ungarische und lateinische Sprichwörter nacheinander vorkommen. Neben 15 Sprichwörtern wird auch die lateinische Entsprechung angegeben, von diesen sind 8 in Sprichwörtersammlungen vorzufinden, z.B.:

„És ebból költ ama régi közmondás: Obsequium amicos, veritas odium parit. Vagyis: A hazugság barátot, az igazság ellenséget szerez." = "mit Schmeichelei und Lügen können wir Freunde gewinnen, aber wenn wir ehrlich sind, wendet sich unser Freund von uns ab.' (Fabeln 64).

Welche ungarischen Varianten im damaligen Sprachgebrauch tatsächlich verbreitet waren und welche nur als okkasionelle ungarische Äquivalente - als Spiegelübersetzungen - entstanden sind, ist schwer zu entscheiden, so z.B. hier:

„Innét támadott a közmondás: Generosi equi non curant latratus canum. Vagyis: Az nemes ló fütyöl az ebugatásra. Eljár útján és keveset gondol avval, hogyan ugatják az ebek." = "man braucht die Verleumdungen und die böswilligen Intrigen gar nicht zu beachten'. (Fabeln 60).

\subsection{RAHMENHAFTE ANORDNUNG}

Der nächste Abschnitt zeigt eine andere Möglichkeit der Einbettung der Sprichwörter im Kotext:

(1) Azt mondják közbeszéddel: A gebét nem illeti a hintószekér.

(2) Tehát mindenki megelégedjék az ô állapotjával és tovább ne nyúljon annál, se ne kévánkozzék többre, mint amire az Isten az ő szent és bölcs akaratjából rendelte.

(3) Mert bizony módja vagyon az Isten akaratjának.

(4) Ámbátor nem is kévánod, az Isten azért megismer tégedet és ha tetszel néki és nagyobb tisztre avagy tisztességre vagy méltó, bizony megtalál.

(5) Ne told magad oda, mert mihelyt te magad kívánod, máris nem vagy méltó reája.

(6) Azért ha odatolod magadat, nyilván úgy jársz, mint ez a szamár.

(7) Mert Mátyás király, Mátyás kovács, mindenik Mátyás, azért különbség vagyon a két Mátyás között.

(8) Magistratus virum monstrat.

(9) Vagyis: A tisztség az ember próbája.

[10. Így vagyon.] (Fabeln 14). 
Zwischen den Sätzen sind die folgenden inhaltlich-logischen Beziehungen festzustellen:

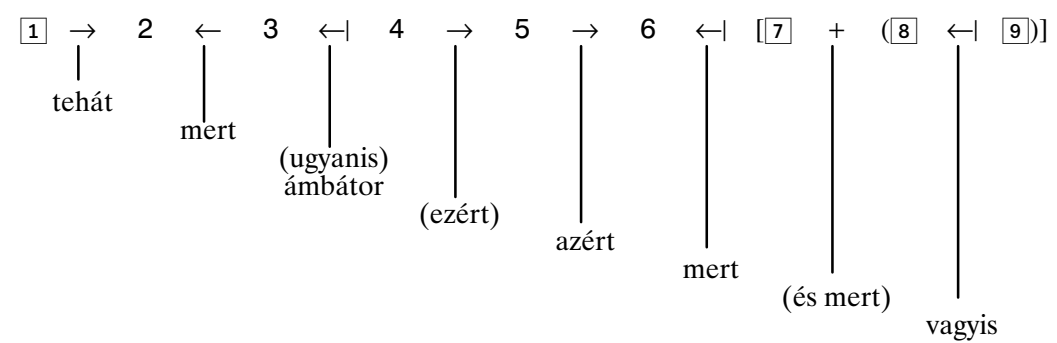

Der Text beruht wieder auf den Ursache-Konsequenz-Zusammenhängen, die Sprichwörter werden aber im Text nicht zerstreut plaziert, wie in dem vorigen Text, sondern sie bilden den Rahmen des Textes. HELTAI leitet mit einem Sprichwort ein, das er in den folgenden fünf Sätzen erläutert, und am Ende der Auslegung faßt er die Lehre der Fabel erneut in zwei Sprichwörtern zusammen, da er darauf basiert, daß das Sprichwort aufgrund seiner allgemeinen Bekanntheit besser im Gedächtnis des Lesers haftenbleibt. Bei dem einen Sprichwort wird sogar das lateinische Äquivalent angegeben. Das Ziel der Häufung der Sprichwörter ist zweifelsohne - wie im vorigen Beispiel - der Aussage einen besonderen Nachdruck zu verleihen. Die Einleitung und die Abschließung des Textes mit Sprichwörtern ist eine überaus geglückte rhetorische Lösung. ${ }^{21}$

Dem Netzdiagramm ist klar zu entnehmen, daß die Sprichwörter nicht so sehr der gedanklichen Vertiefung dienen, sondern auf der Ebene der Grundinformationen erscheinen. Die Sprichwörter bilden die wichtigsten Strukturelemente des Textes: Die übrigen Sätze im Text haben nur die Funktion, zum nächsten Parömium überzuleiten. Die inhaltlichen Zusammenhänge sind so darzustellen:

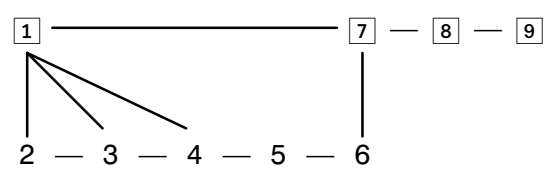

\section{DER EINFLUß DES DEUTSCHEN AUF HELTAIS PHRASEOLOGISMEN}

Nachdem die Einbettung der Sprichwörter behandelt wurde, soll noch zum Schluß auf den eventuellen Einfluß der deutschen Muttersprache HELTAIs auf seine Phraseologismen eingegangen werden. Bekanntlich war HELTAI sächsischer Ab-

${ }^{21}$ Vgl. auch die Forschungsergebnisse von ROZGONYI-MOLNÁR 1982: 355. 
stammung und das Ungarische hat er erst im erwachsenen Alter erlernt. Damit kann erklärt werden, daß in seiner Sprachverwendung manchmal der interferentielle Einfluß des Deutschen zu beobachten ist: In seiner Wortwahl, in der Rektion und vor allem in der falschen Verwendung der ungarischen sogenannten subjektiven und objektiven Konjugation (vgl. VelCsOv 1978: 47-70). Die Annahme liegt also sozusagen auf der Hand, daß der Einfluß des Deutschen auch in der Phraseologie-Verwendung HELTAIs nachzuweisen ist. ${ }^{22}$

Solch eine Untersuchung kann auch deshalb interessant sein, weil viele Belege Heltais in den Sammlungen als Sprichwörter oder als Redewendungen nicht zu identifizieren sind. In solchen Fällen kann angenommen werden, daß diese seitdem ausgestorben sind, oder daß sie Spiegelübersetzungen aus dem Deutschen sind.

5.1. Nach meinen Untersuchungen ist allerdings der Einfluß des Deutschen in der Sprichwort-Verwendung HeltaIs kaum nachzuweisen. Ich habe unter den 75 Sprichwörtern ein einziges gefunden, wo der Einfluß doch anzunehmen ist:

„Azért szokták mondani közbeszéddel: Mikor barátjára az embernek szüksége vagyon, akkor ötven is reáfér egy fontnyi mértékre." = 'wenn man Hilfe braucht, kann man mit seinen Freunden nicht rechnen'. (Fabeln 104).

Es ist nicht ausgeschlossen, daß das Sprichwort im Ungarischen entstanden ist, wahrscheinlicher ist jedoch, das es diesem deutschen Muster folgte:

Freunde in der Not gehen hundert/tausend auf ein Lot = 'in Notzeiten hat man wenige oder keine Freunde'.

Die schriftlichen Quellen bezeugen, daß das deutsche Sprichwort bereits im Mittelhochdeutschen verwendet wurde, so konnte das Sprichwort auch für HELTAI bekannt sein. Dies ist umso wahrscheinlicher, daß die Sprache von Sebastian Brant bei dem das Sprichwort belegbar ist (Narrenschiff. 10,32 - vgl. RÖHRICH 1991: 976), auf HELTAI auch sonst einen Einfluß ausgeübt haben könnte, da es bekannt ist, daß Heltai bei der Fassung seiner Fabeln nicht den lateinischen Text verwendet hat, sondern die Variante der Märchen von Äsop, die am Anfang des XVI. Jahrhunderts eben von Sebastian Brant mit neuen Märchen ergänzt wurde. (Vgl. BEYER/BEYER 1987: 377; KLANICZAY 1964: I/366; RÖHRICH 1991: 976.)

5.2. In den untersuchten fünf Werken habe ich 211 Redewendungen (in 333 Verwendungen) gefunden, von denen nur bei zwei der Einfluß des Deutschen nachzuweisen ist.

„Olly nagy vala ez okaért Máttyás király birodalma, hogy egyfelől, tudnia illik dél felól, határa vala az olasz tenger, északra vala 
a lengyel tenger, napkelet felé kedig a Pontus tenger, napnyugat felé kedig az sváboknak országa. Annyira terjesztötte vala ki Máttyás király az ő királyi birodalmot, és szinte akkoron vala Magyarország az ô virágába és szinte a spiccen. Eszt írhatom kedig Magyarországnak földéról, hogy nem enged semmi földnek mind e széles világon, akar az ô jó egét nézzed, akar az ő népeit, akar az ő termó és gyümölcses vóltát, akar az ő barmait és vadait, akar az ó bányáit és érceit, akar aranyat, ezüstöt, ..." = 'war am Höhepunkt seiner Entwicklung'. (Krónika 30).

Die Redewendung hat nach BARANYAI DECSI (1598/1978: 138) eine negative Bedeutung, d.h. verweist auf Not, Gefahr und Krisensituation, wenigstens darauf kann man aus dem lateinischen Äquivalent schließen: Periculum prorae selis. (Das ungarische etymologische Wörterbuch - NySz. II/1602 - bringt ebenfalls den Beleg von BARANYAI DECSI, doch das lateinische Äquivalent wird hier in Frage gestellt.) Das ungarische etymologische Wörterbuch bringt ebenda auch noch einen anderen Beleg von BARANYAI DECSI (1598/1978: 3/29): Res ad triarios rediit: Szintén az spitzre iutottunk. Die Bedeutung der lateinischen Entsprechung ist wieder ähnlich: 'unsere Lage ist dramatisch schlecht'. Die lateinische Wendung wird so erklärt: die triarios waren die ältesten und sehr erfahrenen Soldaten in der römischen Armee (nach den hastatus und princeps). Wenn sogar sie sich in den Kampf einmischen mußten, um sich den Sieg zu holen, war die Lage wirklich äußerst kritisch (vgl. FINÁLY 1884/1991: 2018).

Aus dem obigen Textzusammenhang ergibt sich aber eben die entgegengesetzte Bedeutung. Die von HeltaI verwendete Wendung zeigt in ihrer Bedeutung einen interferentiellen Einfluß, d.h. folgt ihrem deutschen Muster: Spitze - „(bes. Sport) vordere, führende Position (bes. in Bezug auf Leistung, Erfolg, Qualität): Die Spitze nehmen, halten, abgeben; an der S. liegen, stehen; *an der Spitze von etw. stehen (die höchste Position in einem bestimmten Bereich innehaben): an der S. des Staates stehen; (ugs.) höchste Güte, Qualität (in Bezug auf besonders hervorragende, Begeisterung od. Bewunderung hervorrufende Leistungen): jmd., etw. ist [absolute, einsame] S.“ (vgl. DUW 1989: 1435 f.). In dem Wörterbuch von Jacob und Wilhelm GRIMM (1905/1984: 16/2562 ff.) habe ich auch keine Belege mit negativer Konnotation gefunden.

Die Redewendung ist auch in der Sammlung von O. NAGY zu finden (1976: 601/400): A spiccen van [A spiccre jutott] = 'in größter Not, in größter Gefahr sein'. Die Bedeutung wird allerdings m.E. falsch angegeben, da die Wendung im heutigen Ungarisch einen eindeutig positiven Wert hat.

5.3. Der dritte Beleg ist m.E. der interessanteste und der aufschlußreichste, deshalb sei auf ihn ein wenig ausführlicher eingegangen:

„Mikoron a prokurátor Hispalisba ment volna, beadá leveleit a szent Vadászoknak széki elôtt, és az ő principálisnak marháját visz- 
szakévánja vala. A szent Atyák a hosszú padra kezdék vonni a dolgot, és meghagyják néki, hogy szószólót keresne magának, és írásba foglalná minden dolgát és kívánságit. [...] Mikoron a prokurátor négy egész holnapig ott héjába veszédett volna, úgy adának azután választ néki, müvelhogy hazamenne Angliába, és erősb leveleket hozna...[...] És mikoron azokat beadta volna a szent szék elejbe, a szent Atyák elhalaszták a dolgot. Ez ok alatt, hogy mostan a szent széknek egyéb nagy dolgai volnának. Efféle válaszokkal feltarták a prokurátort, annyira, hogy esmet négy egész holnapig ott mulata hejába." = 'sie mäkeln, verlängern den Verlauf des Prozesses und damit verzögern sie die Entscheidung’. (Háló 234).

Die Wendung hosszú padra vonja a dolgot ist in ungarischen Sammlungen nicht vorzufinden, in den deutschen Sammlungen aber schon, deshalb ist es also mit Recht anzunehmen, daß wir es hier mit einer Spiegelübersetzung zu tun haben. ${ }^{23}$ Die deutsche Vorlage lautet: etwas auf die lange Bank schieben = 'etwas nicht gleich erledigen, aufschieben'.

Die Herkunft der Redewendung ist nicht eindeutig geklärt, soviel scheint aber sicher zu sein, daß sie dem mittelalterlichen Gerichtswesen abstammt. Es wird allerdings diskutiert, was das Wort Bank ursprünglich bedeutete. Diesbezüglich gibt es drei Erklärungsversuche. Diese seien im Folgenden kurz zusammengefaßt.

Nach der einen Auffassung steht Bank in der Wendung als Synonym zu dt. Truhe, und sie bedeutete einen Gegenstand zur Aufbewahrung der Gerichtsakten. Die Redewendung stammt demnach daher, daß die Akten an den Gerichten früher nicht in Schränken, sondern in langen bankähnlichen Truhen aufbewahrt wurden. Die Akten, die hierher gelangt sind, lagen lange unberührt da, während diejenigen, die auf dem Tisch des Richters geblieben sind, schneller bearbeitet wurden. (Nur diese Herkunftserklärung finden wir bei KRÜGER-LORENZEN 1988: 32, genauso auch im Duden 1992: 82.)

Diese Herkunftserklärung bestätigen zahlreiche Belege, so z.B.:

„Aber wir legen die sach in die langen truhen, schertzen mit Gottes wort wie die katz mit der mauß, als lyge nichts darahn, wann wir ein mal darzu thund“.

Sebastian Franck, von dem der Beleg stammt (Von dem greulichen laster der trunkenheit. 1528. - vgl. RöHRICH 1988: 94), war Zeitgenosse von HELTAI. HELTAI hat sogar seine Schriften gekannt, denn die Quelle von seinem Dialógus war eben das deutschsprachige Traktat von Sebastian Franck. So ist es also anzunehmen, daß HELTAI auf seinen Einfluß die Wendung ins Ungarische übertragen hat.

${ }^{23}$ Die Wendung wird sogar in dem heutigen Deutsch verwendet (vgl. Duden 1992: 82). 
Nach einer anderen Erklärung sei es möglich, daß Bank in der Wendung nicht als Synonym zu Truhe auftritt, sondern eine Sitzgelegenheit bedeutet, d.h. bezieht sich auf die Bank im Gerichtssaal, auf dem die Gerichtsbeisitzer, d.h. die Schöffen nach einer bestimmten Reihenfolge Platz genommen haben (vgl. RÖHRICH 1991: 140 ff.). Die Begründung lautet so: Nach dem römischen Recht durfte man mit der Verhandlung vor Sonnenaufgang nicht beginnen, und nach Sonnenuntergang durfte die Verhandlung nicht mehr weitergeführt werden, d.h. im idealen Falle sollte das Urteil bis Sonnenuntergang gefällt werden. Wenn das Gericht bis dahin kein Ergebnis erreicht hat, mußte der Prozeß vertagt werden, so daß ein Gerichtsprozeß sich oft in die Länge gezogen hat.

Wenn aus irgendeinem Grund kein Urteil gefällt werden konnte, konnte der Richter nochmal dieselben Schöffen zusammenrufen, aber er konnte auch noch mehr Schöffen zur Verhandlung einrufen, was dazu führte, daß selbst die Schöffenbank länger wurde. Nach diesem Erklärungsversuch bedeutet also die lange Bank die Schöffenbank, und sie weist darauf hin, daß mit dem Verschieben und Hinauszögern des Gerichtsprozesses selbst diese bestimmte Bank länger wurde. Die Redewendung bekam mit der Zeit eine allgemeine Bedeutung: ,einen Prozeß verlängern, die Entscheidung verzögern'. Diese Etymologie versucht RÖHRICH (1991: 141) mit dem folgenden Beleg zu unterstützen (A. Gryphius 1663: Senyanne 2,1 Teutsche Gedichte I [1698], 859):

„doch damit meine Sache nicht in die lange Bank komme, sondern in kurzer verhör abgehandelt werde".

Der Beleg kann m.E. genauso die erste Entstehungsgeschichte verstärken.

(Das Wörterbuch von Jacob und Wilhelm GRIMM (1854: 1108) bringt die Wendung ebenfalls mit der Schöffenbank in Beziehung - Gerichtsbank, Dingbank, Schöffenbank -, doch erklärt den Entstehungsvorgang nicht näher).

Schließlich nach der dritten - m.E. wenig glaubhaften - Interpretation stand in der Wendung ursprünglich nicht Bank, sondern Bahn in der Bedeutung 'Weg durch die Instanzen' (vgl. MÜLLER 1994: 45). Der Austausch von Bahn durch Bank wird einfach damit erklärt, daß die Gerichtsbank, bzw. die Schöffenbank bildhaft einfacher vorzustellen sei. Diese Annahme will mit einigen Zeilen von Bischof Johann III. aus dem Jahre 1499 unterstützt werden, wo der Bischof über seine Angst spricht, da seine Angelegenheit „alsdann gantz uff die lange Bahn gesetzet würde“ (zitiert von MÜLLER ebenda).

Über die Herkunft der Wendung läßt sich zum Schluß feststellen, daß jede Erklärung zu belegen ist, bzw. die Auswertung der Belege oft fraglich ist, so daß man nicht eindeutig entscheiden kann, welche Entstehungsgeschichte die richtige ist. So konnte meine Aufgabe auch nur darin bestehen, diese zusammenfassend darzustellen. 


\section{ZUSAMMENFASSUNG}

Der Reichtum an Sprichwörtern in HELTAIs Werken ist in erster Linie dem Umstand zu verdanken, daß für den Menschen des XVI. Jahrhunderts Sprichwörter eine nahezu unbeschränkte Gültigkeit hatten. Sie waren Widerspiegelungen der Wertvorstellungen und Normen der Epoche. Sprichwörter machten die Welt anhand ihrer ordnungsbildenden Regeln überschaubar, sie wirkten richtungsweisend und dadurch problemlösend. Für Heltai als Schriftsteller-Prediger kamen sie gerade zurecht, da diese lehrhaften Anmerkungen für jeden verständlich und nicht zu überhören waren. Wie MACKENSEN (1979: 86) sagt, die Sprichwörter „rücken einem auf den Leib, sie lassen sich nicht abschütteln“.

HELTAI verwendet viele Sprichwörter und Redewendungen, die bereits ausgestorben sind, oder im heutigen Ungarisch veraltet oder veraltend wirken, und deshalb einer gewählten Stilschicht angehören. Einige wenige Sprichwörter HELTAIs dagegen gehören sogar zum Bestand des parömiologischen Minimums des heutigen Ungarisch.

Ich bin auch dem Verdacht nachgegangen, daß HELTAIs Phraseologismen Sprichwörter und Redewendungen - als Lehnübersetzungen aus dem Deutschen entstanden sind. Nach meinen Untersuchungen konnte aber festgestellt werden, daß obwohl der Einfluß des Deutschen im Phraseologiegebrauch HELTAIs nachzuweisen ist, doch aufgrund der wenigen Zahl der Belege auf keinen Fall als charakteristisch betrachtet werden kann.

Bei den Möglichkeiten der Einbettung der Sprichwörter im Kotext kann bei HELTAI eine große Vielfalt festgestellt werden. Sprichwörter können literalisiert werden, sie können - besonders synonyme Sprichwörter - gehäuft im Text vorkommen, oder sie können einen Rahmen um den Text herum bilden, indem sie als einleitende und abschließende Formel im Text erscheinen. ${ }^{24}$ Sie können die Grundinformationen des Abschnittes tragen, oder sie können der Vertiefung des Inhaltes dienen. Sie werden immer explizit formuliert, HelTAI begnügt sich nicht mit einem Hinweis auf das Sprichwort, er will in jedem Fall sichergehen, daß er nicht mißverstanden wird. Seine Sprichwörter werden nicht gekürzt, die geschlossene sprachliche Konstruktion wird nicht aufgelöst. Die heute z. B. in den Werbetexten so häufige Anspielung an das Sprichwort oder die sporadische Präsentation des Sprichwortes ist für HELTAI nicht charakteristisch. Für seine Sprache ist am meisten die Häufung von Sprichwörtern typisch. Wie es aus den Textabschnitten zu sehen war, ist die Funktion der Sprichwörter bei Heltai ein wenig sozusagen paradox: Sprichwörter sollten nämlich den Dekodierungsprozeß erleichtern und beschleunigen, stattdessen werden sie bei HELTAI immer wieder - für unseren heutigen Sprachgefühl schon ein wenig umständlich - erläutert. Aber eben dieses Merkmal macht seinen Stil so „sprichwörtlich“.

\footnotetext{
${ }^{24}$ Sie können auch nahezu symmetrisch im Text platziert werden, darauf kann hier aber aus Platzgründen nicht näher eingegangen werden, vgl. z.B. Dialógus 16.
} 


\section{LITERATUR}

HeLtAI, Gáspár

\section{PRIMÄRLITERATUR}

1566/1958: A bölcs Esopusnak és másoknak oktató beszédei valamint azoknak értelme melly fabulákat egybeszerzette és Kolozsvárott anno MDLXVI kiadta Heltai Gáspár most pedig a mai kegyes olvasónak átírta és átnyújtja Keleti Arthur, (Aesops Fabeln...). Budapest: Európa.

1570/1979: Háló. In: Válogatás Heltai Gáspár múveiből. (Netz.) In (Ausgewählte Werke von G. Heltai). Budapest: Magvető, 91-291.

1552/1980: A részegségnek és tobzódásnak veszedelmes voltáról való dialógus. (Streitschrift über die Gefährlichkeit der Betrunkenheit und der Völlerei in Werken von G. Heltai und P. Bornemisza). In: Heltai Gáspár és Bornemisza Péter múvei. Budapest: Szépirodalmi, 9-65.

1572/1980: Ponciánus császár históriája. (Historia des Kaisers Ponciani in Werken von G. Heltai und P. Bornemisza). In: Heltai Gáspár és Bornemisza Péter múvei. Budapest: Szépirodalmi, 271405.

1575/1981: Krónika az magyaroknak dolgairól. (Ungarische Chronik). Budapest: Magyar Helikon.

BARANYAI DECSI, János

\section{SEKUNDÄRLITERATUR}

1598: Adagiorum Graecolatinoungaricorum chiliades quinque. Bártfa.

BARÓTI SZABÓ, Dávid

1803: A magyarság virági (Wortblüten der Ungarn). Komárom.

BÉKÉSI, Imre

1982: Szövegszerkezeti alapvizsgálatok (magyar újsághíranyag alapján) (Textstrukturen anhand der ungarischen Presse). Budapest: Akadémiai.

BENCÉDY, József/FÁBIÁN, Pál/RÁCZ, Endre/VElCsov, Mártonné

1985: A mai magyar nyelv (Ungarisch von heute). Budapest: Tankönyvkiadó.

BEYER, Horst/BEYER, Annelies

1987: Sprichwörterlexikon. Leipzig: VEB Bibliographisches Institut.

BURGER, Harald

1973: Idiomatik des Deutschen. Tübingen: Max Niemeyer Verlag.

DeME, László

1965: A mondatok egymáshoz kapcsolódása a beszédben (Verbindungen der Sätze in der Rede). In: Magyar Nyelvő́r LXXXIX, 292-302.

1971: Mondatszerkezeti sajátságok gyakorisági vizsgálata (Untersuchungen über Häufigkeit der Satztypen). Budapest: Akadémiai.

DETJE, Frank

1995: Die Bedeutung der Sprichwörter für das menschliche Handeln. In: PROVERBIUM, Yearbook of International Proverb Scholarship 12, 97-118.

DÖMÖTÖR, Ákos

1989: Közmondás-paródiák (Sprichwort-Parodien). In: Magyar Nyelvőr CXIII, 128.

Duden

1992 = Der Duden: in 12 Bänden. Bd. 11 - Redewendungen und sprichwörtliche Redensarten. Wörterbuch der deutschen Idiomatik. Hrsg. und bearb. von G. DROSDOWSKI und W. SCHOLZE-STUBENRECHT, Mannheim/Leipzig/Wien/Zürich: Dudenverlag.

DUW

Duden Deutsches Universalwörterbuch. Hrsg. und bearb. vom Wiss. Rat u.d. Mitarb. d. Dudenred. unter Leitung von Günther DROSDOWSKI, 1989, Mannheim/Wien/Zürich: Dudenredaktion.

ERDÉLYI, János

1851: Magyar közmondások könyve (Buch der ungarischen Sprichwörter). Pest.

FINÁLY, Henrik

1884/1991: A latin nyelv szótára (Wörterbuch der lateinischen Sprache). Budapest: Franklin Társulat Magyar Irod. Intézet és Könyvnyomda.

FLEISCHER, Wolfgang

1982: Phraseologie der deutschen Gegenwartssprache. Leipzig: VEB Bibliographisches Institut. 
FLEISCHER, W./HARTUNG, W./SCHILDT, J./SUCHSLAND, P. (Hrsg.)

1983: Kleine Enzyklopädie „Deutsche Sprache“. Leipzig.

FORGÁCS, Erzsébet

1996: Spielerische Verwendung vorgeprägter Sprachformeln (Literalisierung in der Werbesprache und in Witzen). In: PONGÓ, Štefan (Hrsg.): Kontaktsprache Deutsch (Sammelband der germanistischen Tagung Nitra-Passau am 26. und 27. Oktober 1995 in Račková dolina), Nitra, 85103.

1997a: Im Sprichwort liegt die Wahrheit (?) - Zur spielerischen Verwendung von Sprichwörtern und geflügelten Worten. In: Beiträge zur Fremdsprachenvermittlung, Konstanz, 1997/31, 7888.

1997b: Proverbiumok a reklám nyelvében (Proverbien in der Sprache der Werbung). In: Magyar Nyelv 1997/3, 360-366.

1997c: Sprichwortabwandlungen in der Werbesprache. In: Germanistik, Luxembourg, 1997/XI, 7195.

1997d: Német mintára keletkezett frazémák Heltai Gáspár múveiben (Phraseme nach deutschem Muster in den Werken von G. Heltai). In: Magyar Nyelv 1997/4, 454-456.

GRIMM, Jacob/GRIMM, Wilhelm

1905/1984: Deutsches Wörterbuch. München.

HADROVICS, László

1995: Magyar frazeológia. Történeti áttekintés (Ungarische Phraseologie. Ein historischer Überblick). Budapest: Akadémiai.

HÄUSERMANN, J.

1977: Phraseologie. Hauptprobleme der deutschen Phraseologie auf der Basis sowjetischer Forschungsergebnisse. Tübingen.

HERNÁDI, Miklós

1976: Közhelyszótár (Wörterbuch der Gemeinplätze). Budapest: Gondolat.

HESSKY, Regina

1992: Grundfragen der Phraseologie. In: ÁGEL, Vilmos/HessKY, Regina (Hrsg.): Offene Fragen offene Antworten in der Sprachgermanistik. Tübingen, 77-93.

JUHÁsZ, József

1980: A frazeológia mint nyelvészeti diszciplína. In: Tanulmányok a mai magyar nyelv szókészlettana és jelentéstana köréből (Die Phraseologie als sprachwissenschaftliche Disziplin). (Studien zu Wortschatz und Semantik der heutigen ungarischen Sprache). 79-97.

KERTÉSZ, Manó

1985: Szokásmondások (Gebrauchssprichwörter). Budapest: Helikon.

KLANICZAY, Tibor (Hrsg.)

1964: A magyar irodalom története (Geschichte der ungarischen Literatur). Budapest: Akadémiai.

KOLLER, Werner

1977: Redensarten. Linguistische Aspekte, Vorkommensanalysen, Sprachspiel. Tübingen: Max Niemeyer Verlag.

KRÜGER-LORENZEN, Kurt

1988: Deutsche Redensarten und was dahinter steckt. Düsseldorf/Wien: Wilhelm Heyne Verlag.

MACKENSEN, Lutz

1985: Gutes Deutsch in Schrift und Rede. München: Mosaik Verlag.

MARGALITS, Ede

1897/1990: Magyar közmondások és közmondásszerû szólások (Ungarische Sprichwörter und sprichwörtliche Redensarten). Budapest: Akadémiai.

MATTA, Hilda

1988: Das Sprichwort. Versuch einer Definition. In: PROVERBIUM, Yearbook of International Proverb Scholarship 5, 69-84.

MülLER, Klaus

1994: Lexikon der Redensarten. München.

NySz. = SZARVAS, Gábor/SIMONYI, Zsigmond

1890: Magyar nyelvtörténeti szótár (Ungarisches Etymologisches Wörterbuch). Budapest: Hornyánszky Viktor Akadémiai Könyvkereskedése.

O. NAGY, Gábor

1976: Magyar szólások és közmondások (Ungarische Redensarten und Sprichwörter). Budapest: Gondolat. 


\section{O. NAGY, Gábor}

1977: A magyar frazeológiai kutatások története (Geschichte der ungarischen phraseologischen Untersuchungen). Nyelvtudományi Értekezések 95, Budapest.

ROZGONYI-MOLNÁR, Emma

1978: Logikai relációk kifejezése hálódiagrammal a szöveg és a mondat vizsgálatában (Logische Relationen im ungarischen Text- und Satzbau). In: Magyar Nyelvőr 102, 352-363.

1982: A szólások és közmondások szövegbe szerkesztése (Texteinbettung von Redensarten und Sprichwörtern). In: Magyar Nyelvőr CVI, 352-356.

RÖHRICH, Lutz

1988: Lexikon der sprichwörtlichen Redensarten. Freiburg/Basel/Wien: Herder.

1991: Das große Lexikon der sprichwörtlichen Redensarten. Freiburg/Basel/Wien: Herder.

SZATHMÁRI, István

1996: Újabb szólásainkról (Über unsere neuere Sprichwörter). In: Magyar Nyelv XCII, 458-461.

SZEMERKÉNYI, Ágnes

1988: Közmondás és szólás (proverbium) [Sprichwort und Redensart (Proverbium)] In: Magyar Néprajz V. Népköltészet. (Ungarische Volkskunde. Band V. Volksdichtung). Budapest: Akadémiai, 213-237.

1994: „Közmondás nem hazug szólás“ (A proverbiumok használatának lehetőségei) („Sprichwortkein falsches Wort“. Zu den Möglichkeiten der Anwendung von Sprichwörtern). Budapest: Akadémiai.

TOLNAI, Vilmos

1910: A szólásokról (Über die Redensarten). A Magyar Nyelvtudományi Társaság Közleményei 12.

1935: Szólások. (Szóláshasonlat, szólásmód és közmondás) [Redensarten. (Phraseologischer Vergleich, Redewendung und Sprichwort) In: Magyarság Néprajza (Ungarische Volkskunde). III., Budapest, 397-433.

Tóth-LiTOVKINA, Anna

1996: Parömiológiai felmérés Magyarországon (Milyen formában és változatban élnek a legismertebb közmondások, és mi határozza meg az ismeretüket?) (Befragung zu den Parömien in Ungarn. In welcher Form und in welchen Varianten leben die bekanntesten ungarischen Sprichwörter und was determiniert ihre Bekanntheit?) In: Magyar Nyelv 1996/4, 439-458.

VELCSOV, Mártonné

1978: Heltai Gáspár német anyanyelvének nyomai magyar nyelvú múveiben (Die Spuren der deutschen Muttersprache Gáspár Heltais in seinen ungarischen Werken). In: Néprajz és Nyelvtudomány XXII-XXIII, 47-70. 